4. Krueger T, Chassot PG, Christodoulou M, Cheng C, Ris HB, Magnusson L. Cardiac function assessed by transesophageal echocardiography during pectus excavatum repair. Ann Thorac Surg. 2010;89:240-3.
5. Lesbo M, Tang M, Nielsen HH, Frøkiær J, Lundorf E, Pilegaard HK, et al Compromised cardiac function in exercising teenagers with pectus excavatum. Interact Cardiovasc Thorac Surg. 2011;13:377-80.

\title{
Delayed esophageal diverticulum formation after stent-based treatment of perforation
}

\author{
Meghana R. Kunkala, MD, and Claude Deschamps, MD, Rochester, Minn
}

Epiphrenic diverticula are rare. Presenting symptoms often include dysphagia, regurgitation, chest pain, and heartburn. Intermittent episodes of aspiration, mostly nocturnal, are not uncommon. ${ }^{1}$ Some diverticula, however, are completely asymptomatic or present with minimal symptoms. In a series of 112 patients with diverticula, $42 \%$ were completely free of symptoms. ${ }^{2}$

The etiology of these diverticula is greatly debated. Most are pulsion pseudodiverticula and are thought to be secondary to an increase in intraesophageal pressure. An associated motility disorder is often present. In fact, Tedesco and colleagues ${ }^{1}$ found that 17 of 21 patients presenting with diverticula had an associated motility disorder, such as achalasia, diffuse esophageal spasm, or a nonspecific esophageal motility disorder. Surgical treatment is offered on the basis of the presence of symptoms and resulting complications and often includes a myotomy to address the motility disorder. ${ }^{3}$

Diverticula formation after esophageal perforation, specifically after esophageal perforation treated with stent placement, has not previously been reported in the literature. The vast majority of esophageal perforations have been treated surgically. In select cases, however, selfexpanding stents have been introduced into the management of patients with esophageal perforations, with mixed outcomes. ${ }^{4-6}$ A meta-analysis of 75 studies shows a $14.8 \%$ pooled mortality for spontaneous perforations, with stenting associated with lower mortality $(7.3 \%)$, although this is likely biased by patient selection. ${ }^{5}$ Serious complications, such as respiratory insufficiency, mediastinal emphysema, ulceration secondary to stents, and migration of stents, have all been reported in patients undergoing stent placement for symptomatic management of esophageal

From the Division of Thoracic Surgery, Mayo Clinic, Rochester, Minn.

Disclosures: Authors have nothing to disclose with regard to commercial support.

Received for publication July 12, 2013; revisions received Aug 22, 2013; accepted for publication Aug 29, 2013; available ahead of print Oct 21, 2013.

Address for reprints: Claude Deschamps, MD, Division of Thoracic Surgery, Department of Surgery, Mayo Building 12W, Mayo Clinic, 200 First St SW, Rochester,

MN 55905 (E-mail: deschamps.claude@ mayo.edu).

J Thorac Cardiovasc Surg 2014;147:e5-8

$0022-5223 / \$ 36.00$

Copyright (C) 2014 by The American Association for Thoracic Surgery

http://dx.doi.org/10.1016/j.jtcvs.2013.08.077

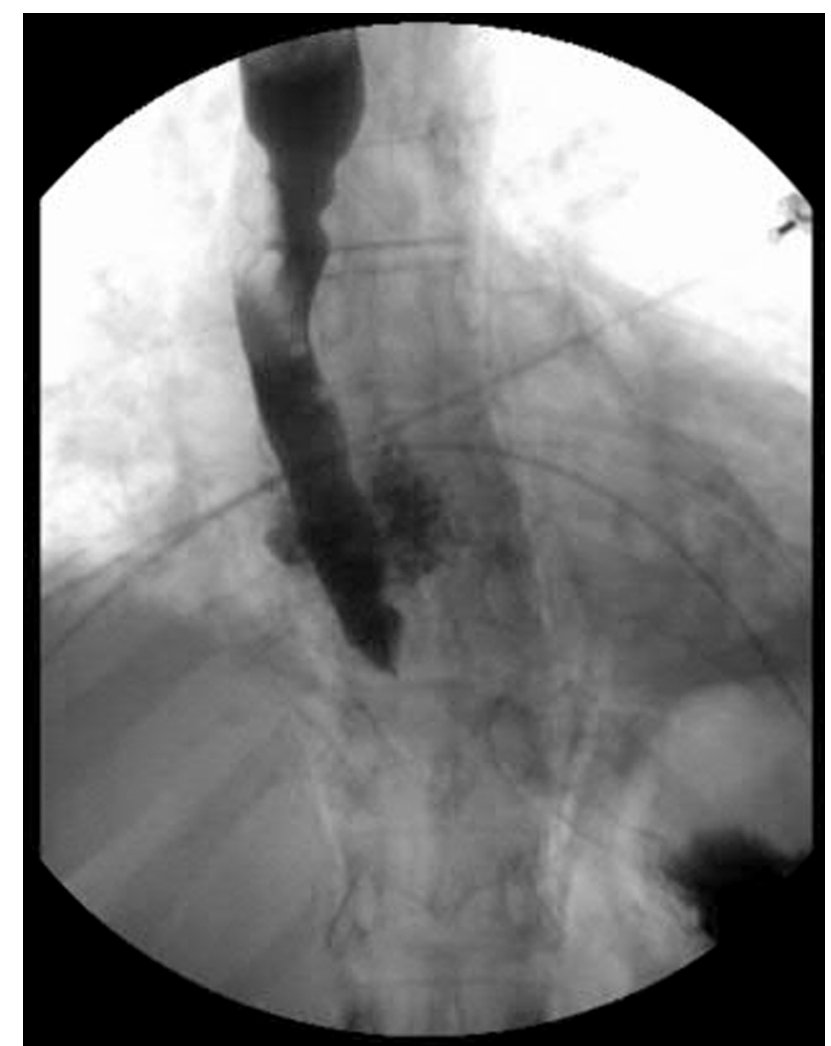

FIGURE 1. Initial esophagogram demonstrating distal esophageal perforation.

cancer. $^{7}$ No studies to date, however, have analyzed midterm to long-term complications of stent management of spontaneous esophageal perforation. We present a case of delayed esophageal diverticula formation after spontaneous esophageal perforation managed with stent placement.

\section{CLINICAL SUMMARY}

An 82-year-old woman was seen at an outside institution with abrupt onset of left upper quadrant abdominal pain after ingestion of a cup of coffee. The pain radiated to her back. A computed tomographic scan was obtained and showed a pneumomediastinum; this prompted an esophagogram, which showed evidence of a distal esophageal perforation and normal motility of the 


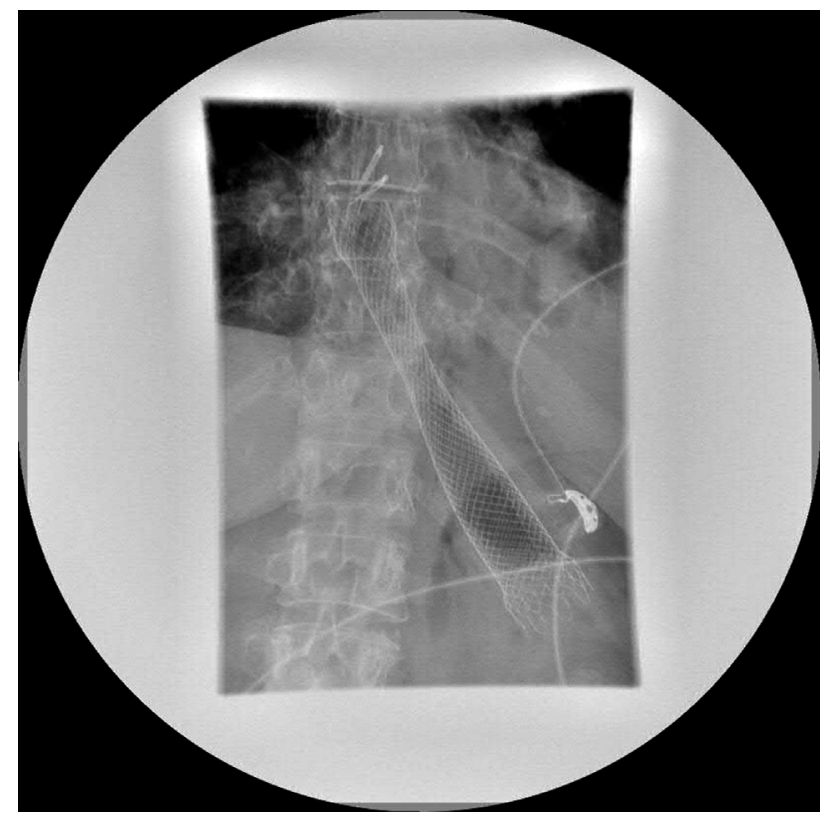

FIGURE 2. An esophagogram showing stent placement after spontaneous esophageal perforation.

esophagus (Figure 1). The patient was subsequently transferred to our institution. She was resuscitated and stabilized, after which an upper endoscopy was performed. The upper endoscopy showed an obvious perforation of the esophagus, approximately $5 \mathrm{~mm}$ in size at a distance of $30 \mathrm{~cm}$ from the incisors. No other abnormalities, such as strictures or ulcerations, were noted. The esophagus was not dilated at any portion. A 10-cm fully covered Boston Scientific (Natick, Mass) esophageal stent was placed and centered at the $30-\mathrm{cm}$ level and secured with hemoclips. The body of the stent was $23 \mathrm{~mm}$ in diameter, and the proximal and distal flared portions were $28 \mathrm{~mm}$. An esophagogram was performed the next day with no evidence of esophageal leak (Figure 2). No esophageal physiology testing was done during this hospitalization. The patient was discharged home 5 days after stent placement with prophylactic antibiotics.

The patient returned for esophageal stent removal 2 months later. An irregular area of dimpling was diagnosed as a possible pseudodiverticulum (Figure 3). The patient was referred back 2 months later with continued regurgitation. An esophagogram showed a large diverticulum (Figure 4). The patient was taken to the operating room for a diverticulectomy because of her ongoing symptoms.

The diverticulectomy was approached through a right posterolateral thoracotomy in the sixth interspace. On opening of the chest, there was some bulging at the level of the anticipated diverticulum, which was tethered to the chest wall but not so much so that it was difficult to isolate. The diverticulum was isolated and dissected from the esophagus. The muscularis at the level of the diverticulum

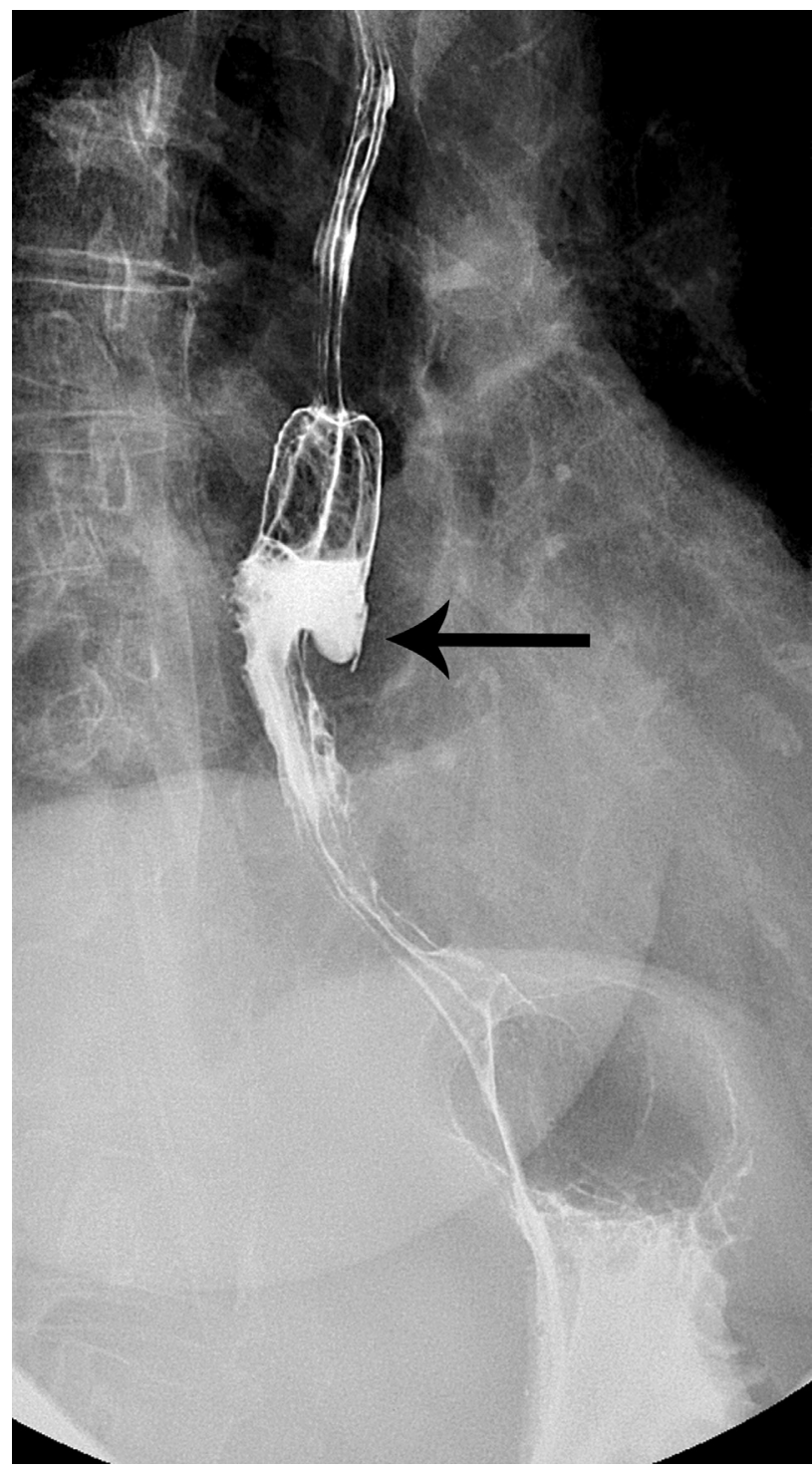

FIGURE 3. An esophagogram showing a diverticulum at the time of stent removal (arrow).

was almost completely circumferentially absent. Of note, the lining included all layers of the esophagus, making this a true diverticulum. ATA-60 4.8-mm stapler (Covidien, Mansfield, Mass) was used to remove the majority of the diverticulum, over a $50 \mathrm{~F}$ bougie, leaving only a small mucosal cuff. At this point, we thought it best to support the muscularis to prevent early recurrence.

The parietal pleura was dissected off the chest wall but left attached to the aorta for continued vascular supply. The parietal pleura was then rotated and used as a "sleeve" around the most attenuated portion of the muscularis and was incorporated into the suture line that was used to buttress the staple line (Figure 5). A myotomy was not performed as part of the operation, because we did not believe this patient had a motility disorder or that a motility disorder was the cause of the diverticulum. Specifically, 


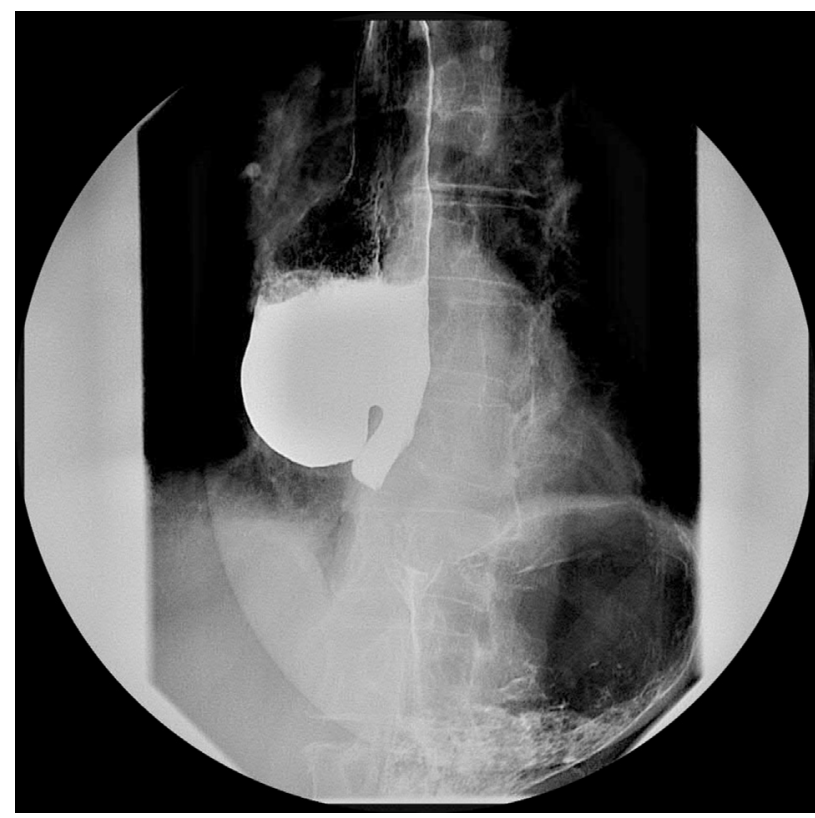

FIGURE 4. An esophagogram showing the now larger diverticulum before the operation.

the muscularis was not thickened, which we would have expected if a motility disorder had been present.

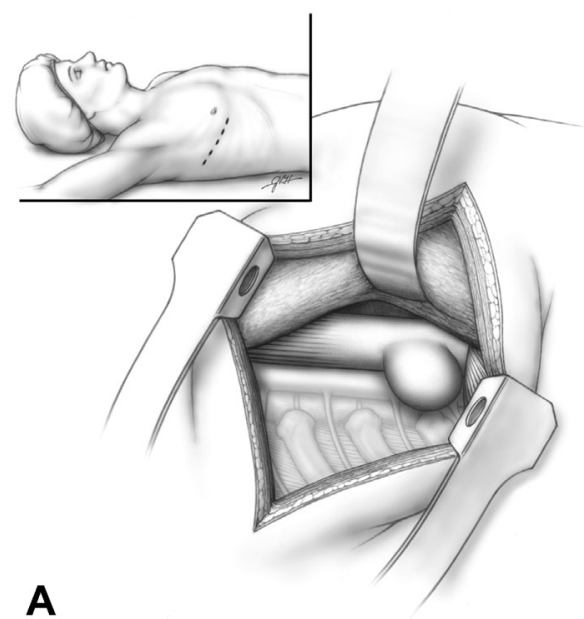

A

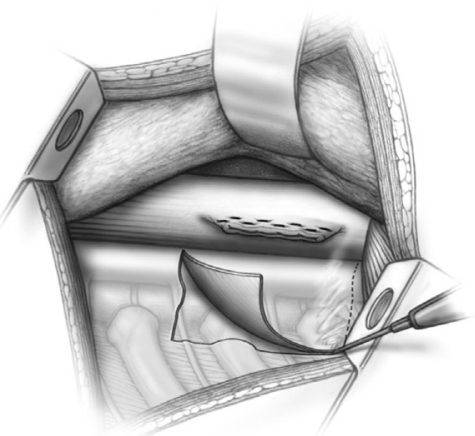

\section{C}

The patient did well postoperatively, other than atrial fibrillation on postoperative day 2 , which was controlled with amiodarone. An esophagogram was obtained on postoperative day 3 and showed no evidence of a leak (Figure 6).

\section{DISCUSSION}

Epiphrenic diverticula are rare and are usually associated with a motility disorder. We present what we believe to be the first reported case of a true diverticulum after esophageal perforation and stent placement. The pathophysiology of this entity is not well characterized. Although it may be hard to explain the mechanism of diverticulum formation in this patient, we do have a theory. One possibility is that the area where the diverticulum was located was likely weakened, as it did spontaneously perforate. Taking at baseline a weakened area and adding to it the inflammatory cascade that occurred after perforation resulted in a diverticulum. The endoscopy on stent removal did show a "dimpling" at the area of perforation. This demonstrates that the healing process was likely inflammatory in nature and that this lesion could have acted much like an inflamed lymph node does in the development of a traction diverticulum. Although neither the diverticulum nor the esophagus was tough to isolate, there were some adhesions

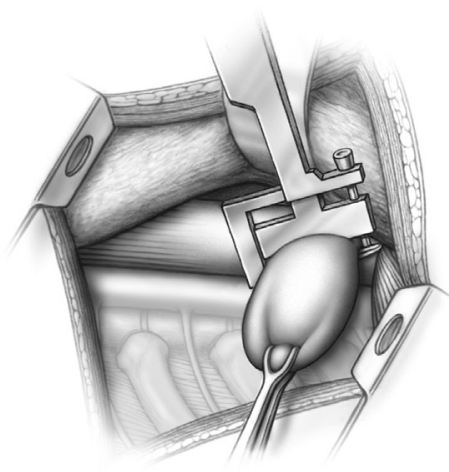

B

\section{D}

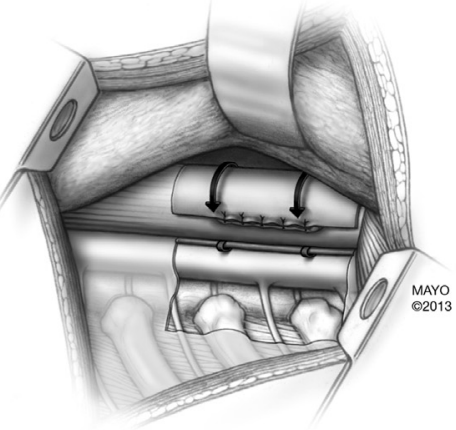

FIGURE 5. An illustration outlining the steps of the operation. A, A right posterolateral thoracotomy was made in the sixth interspace, at which point the diverticulum was noted along with a weakened muscularis layer. B, A TA-60 4.8-mm stapler (Covidien, Mansfield, Mass) was used to remove the majority of the diverticulum, leaving only a small cuff. C, The parietal pleura was used as a vascularized flap. D, The flap was incorporated into the suture line, which was used to buttress the staple line. 


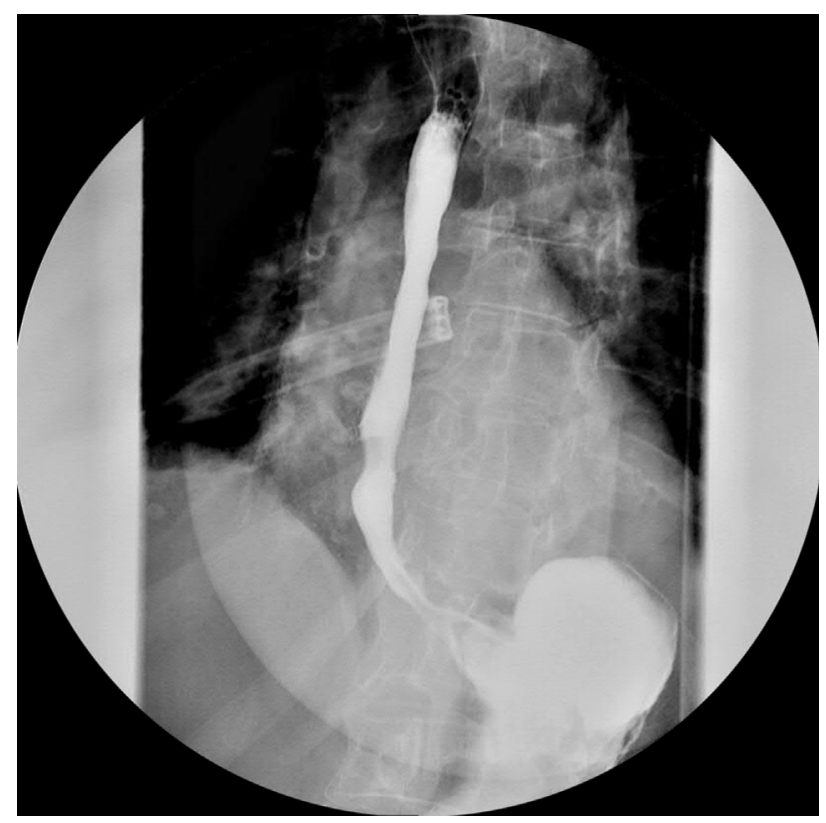

FIGURE 6. An esophagogram showing no diverticulum or leak 3 days after the operation.

to the chest wall that needed to be taken down. Pulsion diverticula are more common at this location; however, we did note all layers of the esophagus in the diverticulum (although the muscularis was attenuated), making this a true diverticulum.

There might also be some abnormalities in esophageal peristalsis at the time of the initial leak secondary to the inflammation in the area. Akin to changes in small bowel motility after resection, esophageal peristalsis may have been altered after perforation. We have no literature that sheds light on how esophageal peristalsis is affected by stent placement, but there may be some changes that need to be studied further.

Esophageal stents have changed the management of patients with esophageal perforations. In selected cases, they help to avoid major surgical interventions and the accompanying morbidity and mortality. Little is known, however, regarding the long-term complications of treating esophageal perforations with these minimally invasive approaches. In light of our findings, further studies looking at the early, intermediate, and long-term complications of esophageal stenting for the management of spontaneous perforation are needed to clearly establish the risk for poststent esophageal diverticulum formation.

We thank John Hagen for his excellent illustrations of the surgical procedure.

\section{References}

1. Tedesco P, Fisichella PM, Way LW, Patti MG. Cause and treatment of epiphrenic diverticula. Am J Surg. 2005;190:891-4.

2. Benacci JC, Deschamps C, Trastek VF, Allen MS, Daly RC, Pairolero PC Epiphrenic diverticulum: results of surgical treatment. Ann Thorac Surg. 1993; 55:1109-13; discussion 1114

3. Orringer MB. Epiphrenic diverticula: fact and fable. Ann Thorac Surg. 1993;55: 1067-8.

4. Kiernan PD, Sheridan MJ, Elster E, Rhee J, Collazo L, Byrne WD, et al. Thoracic esophageal perforations. South Med J. 2003;96:158-63.

5. Biancari F, D'Andrea V, Paone R, Di Marco C, Savino G, Koivukangas V, et al. Current treatment and outcome of esophageal perforations in adults: systematic review and meta-analysis of 75 studies. World J Surg. 2013;37:1051-9.

6. Schweigert M, Beattie R, Solymosi N, Booth K, Dubecz A, Muir A, et al. Endoscopic stent insertion versus primary operative management for spontaneous rupture of the esophagus (Boerhaave syndrome): an international study comparing the outcome. Am Surg. 2013;79:634-40.

7. Radecke K, Gerken G, Treichel U. Impact of a self-expanding, plastic esophageal stent on various esophageal stenoses, fistulas, and leakages: a single-center experience in 39 patients. Gastrointest Endosc. 2005;61:812-8.

\section{Acute inferior wall myocardial infarction secondary to ruptured sinus of Valsalva aneurysm in a 22-year-old man}

Hui-Ping Sun, MD, Xiang Ma, PhD, Xue Bai, MD, Karmacharya Ujit, MD, and Yi-Tong Ma, PhD, Ürümqi, China

\footnotetext{
From the First Affiliated Hospital of Xinjiang Medical University, and Xinjiang Key Laboratory of Cardiovascular Disease Research, Ürümqi, China.

Disclosures: Authors have nothing to disclose with regard to commercial support.

Hui-Ping Sun and Xiang Ma share the position of first author and they also share joint authorship.

Received for publication July 4, 2013; revisions received Aug 25, 2013; accepted for publication Sept 6, 2013; available ahead of print Oct 30, 2013.

Address for reprints: Yi-Tong $\mathrm{Ma}, \mathrm{PhD}$, Cardiology, First Affiliated Hospital of Xinjiang Medical University, Ürümqi, Xinjiang 830054, China (E-mail: myt-xj@163.com).

J Thorac Cardiovasc Surg 2014;147:e8-10

$0022-5223 / \$ 36.00$

Copyright (c) 2014 by The American Association for Thoracic Surgery

http://dx.doi.org/10.1016/j.jtcvs.2013.09.020
}

Sinus of Valsalva aneurysm (SVA), a rare condition of thinning of the wall of the aortic sinus, usually enlarges with time and remains undetected until rupture. After rupture, SVAs may protrude into any heart chamber, more commonly the right atrium or ventricle, or rupture into the pulmonary artery or interventricular septum. Those that remain unruptured are typically asymptomatic hence easily ignored. We report a case highlighting the importance of recognition of atypical manifestations of the disease. 